\title{
TRANSPLANTE DE PÂNCREAS EM DIABÉTICOS TIPO I NÃO URÊMICOS RELATO DOS DOIS PRIMEIROS CASOS DO RIO GRANDE DO SUL
}

\author{
Pancreas Transplant Alone for Non-Uremic Type I Diabetes - Report of the two first Cases on RS
}

\author{
Salvador Gullo-Neto', David Saitovitch², Marcelo Junges Hartmann², Moacir Alexandre Traese/ ${ }^{3}$, \\ José Mario de Carvalho4, José Eduardo Queiroz de Carvalho'2, Eduardo Martins de Carvalho ${ }^{5}$, \\ Leonardo Kroth ${ }^{5}$, Giancarlo Munaretto ${ }^{6}$, Carlos Eduardo Poli de Figueiredo ${ }^{2}$, Domingos D'Ávila ${ }^{2}$
}

\begin{abstract}
RESUMO
O artigo tem como objetivo, relatar os primeiros casos de transplante isolado de pâncreas realizados no estado do RS, discutir suas indicações e resultados. Caso 1 - Feminino, 32 anos, diabética tipo I desde os 17 anos, controle metabólico inadequado e complicações crônicas do Diabetes Mellitus. Transplante realizado no dia 12 de fevereiro de 2003 no Hospital São Lucas da PUC-RS. Caso 2 - Feminino, 29 anos, diabética tipo I desde os 14 anos, com controle metabólico difícil e complicações crônicas do Diabetes Mellitus. Transplante realizado dia 2 de março de 2003. Os enxertos foram implantados por técnica sistêmica-vesical. Esquema de imunossupressão quádruplo (terapia de indução, tacrolimus, MMF e prednisona). Ambas as pacientes evoluíram satisfatoriamente, com excelente controle metabólico ao final do primeiro ano após o transplante. Concluímos que, em casos bem selecionados, o transplante de pâncreas isolado é um método efetivo no controle do Diabetes Mellitus tipo I complicado.
\end{abstract}

Descritores: Transplante de pâncreas, Transplante isolado de pâncreas.

\footnotetext{
Trabalho realizado no Serviço de Nefrologia e Cirurgia Geral - Equipe de Transplantes - Hospital São Lucas - PUCRS - Porto Alegre - RS.

1. Cirurgião do Programa de Transplante de Pâncreas HSL-PUCRS:

2. Nefrologista do Programa de Transplante de Pâncreas HSL-PUCRS e Prof. da FAMED:

3. Nefrologista do Programa de Transplante de Pâncreas do HSL-PUCRS:

4. Cirurgião do Programa de Transplante de Pâncreas do HSL-PUCRS e Prof. da FAMED:

5. Residentes da Nefrologia do Hospital São Lucas da PUCRS:

6. Acadêmico da FAMED - PUCRS.

Endereço para correspondência: Prof. Dr. David Saitovitch - Av. Ipiranga, 6690 - $3^{\circ}$ Andar Hemodiálise - Bairro Jardim Botânico - CEP 90610-000 - Porto Alegre - RS - Brasil Fone: (51) 3336-7700 - E-mail: dsaitov@zaz.com.br

Recebido em: 30/06/2003 Aceito em: 05/01/2005
}

\section{INTRODUÇÃO}

O transplante de pâncreas (TP) é a única terapia capaz de promover controle metabólico rigoroso e permanente nos pacientes portadores de Diabetes Mellitus (DM) tipo I. ${ }^{1}$ Inicialmente introduzido na transplantação simultânea com o rim, nos pacientes já portadores de doença renal crônica terminal, o TP demonstrou ser um método seguro e eficaz no controle do metabolismo dos glicídios e na melhora da qualidade de vida dos pacientes. ${ }^{2} \mathrm{Na}$ última década, vários centros transplantadores passaram a indicar o TP isoladamente. Esta nova modalidade foi proposta para os pacientes com controle metabólico muito difícil, apesar de tratamento clínico adequado e nos portadores de hipoglicemia assintomática. ${ }^{3}$ Os resultados foram extremamente satisfatórios, o que possibilitou ampliar os limites para a indicação desta modalidade de TP. Notou-se que, além de obter um ótimo controle metabólico, alguns estudos demonstraram que o TP alterou o curso das complicações crônicas do DM. ${ }^{4,5,6,7,8,9}$ Desta forma, passou-se a indicar o TP isolado numa fase mais precoce do aparecimento das complicações crônicas do DM, na expectativa de modificar o curso natural desta doença. ${ }^{10} \mathrm{Em}$ nosso programa, indicamos o TP isolado quando os pacientes apresentam duas ou mais complicações crônicas do DM documentadas por exames complementares e/ou se tiverem o diagnóstico endocrinológico de hipoglicemia assintomática ou Diabetes hiperlábil.

\section{Caso Clínico 1}

Paciente feminina, branca, 32 anos, do lar, encaminhada ao nosso serviço por apresentar difícil controle metabólico do DM, apesar 
de tratamento clínico adequado. Apresentava também, retinopatia proliferativa, neuropatia periférica grave e nefropatia diabética (DCE - $60 \mathrm{ml} / \mathrm{min}$ e proteinúria de $2,0 \mathrm{gr} / 24 \mathrm{~h}$ ). Utilizava $40 \mathrm{UI}$ de insulina NPH divididas em 3 aplicações diárias. Transplante realizado em 12 de fevereiro de 2003 com técnica sistêmica-vesical, sem intercorrências. Com relação ao esquema imunossupressor, empregamos o daclizumab ( $2 \mathrm{mg} / \mathrm{Kg} / \mathrm{dose}$ nos dias 0 e 14) como terapia de indução. $\mathrm{O}$ esquema de manutenção utilizado foi com tacrolimus, micofenolato mofetil e prednisona. A paciente cursou com excelente controle metabólico desde o pós-operatório imediato, sem necessidade de insulina exógena. Apresentou, no sétimo dia pós-operatório, elevação das enzimas pancreáticas e queda da amilase urinária. Uma biópsia pancreática evidenciou rejeição celular aguda grau II de Drachemberg que foi tratada com OKT3 por 10 dias. Desde a alta hospitalar, a paciente mantém excelente controle metabólico (insulino-independente), sem outras complicações e sem necessidade de insulina exógena, estando atualmente com 1 ano e 2 meses de seguimento.

\section{Caso Clínico 2}

Paciente feminina, branca, 29 anos, auxiliar de logística, encaminhada ao nosso serviço por apresentar difícil controle metabólico do DM, apesar de tratamento clínico adequado. Apresentava como complicação crônica do DM retinopatia não proliferativa, neuropatia periférica grave e nefropatia diabética (proteinúria de $620 \mathrm{mg} / 24 \mathrm{~h}$ e DCE de $48 \mathrm{ml} / \mathrm{min}$ ). Utilizava 38 UI de insulina NPH divididas em 4 aplicações diárias. Transplante realizado em 2 de março de 2003 pela mesma técnica anteriormente citada, sem intercorrências. Como agente de indução, empregamos o OKT3 na dose de $10 \mathrm{mg} /$ dia por 10 dias. $\mathrm{O}$ esquema imunossupressor de manutenção utilizado também foi à base de tacrolimus, micofenolato mofetil e prednisona. A paciente cursou com excelente controle metabólico no período pós-operatório imediato, sem necessidade de insulina exógena. Permanece até hoje, 1 ano após o transplante, insulinoindependente sem maiores intercorrências.

Em ambos os casos relatados, o tempo médio de cirurgia foi de 3,5 horas. As duas pacientes estão com mais de um ano de acompanhamento e a complicação mais freqüentemente observada pela equipe foi a infecção urinária. Nenhuma outra complicação urológica foi descrita neste período de seguimento. A prevenção da acidose metabólica e desidratação foi evitada com a estimulação da ingesta hídrica e a reposição de citrato de sódio 3 vezes ao dia. Durante este ano, ambas as pacientes mantiveram a função renal estável, apesar do uso de inibidor da calcineurina no seu esquema imunossupressor.

\section{DISCUSSÃO}

Inicialmente, o TP isolado só era indicado para os pacientes com hipoglicemia assintomática, naqueles pacientes que tinham um controle metabólico ruim apesar de tratamento clínico adequado e nos pacientes com incapacidade psicológica de lidar com a insulinoterapia. ${ }^{3}$ Os resultados iniciais não eram tão satisfatórios como nos transplantes simultâneos de pâncreas-rim, ${ }^{11}$ principalmente pela maior dificuldade em se diagnosticar rejeição aguda. Nesta fase inicial, a sobrevida de enxertos pancreáticos transplantados isoladamente atingia índices de sobrevida de $70 \%$ ao final do primeiro ano. ${ }^{11}$ A melhora nos resultados desta categoria de TP se deve aos novos esquemas imunossupressores utilizados e às modificações introduzidas nas técnicas cirúrgicas. No final da década de 90 , alguns centros já relatavam sobrevida de enxertos semelhantes entre o transplante isolado de pâncreas e o simultâneo com o rim, ou seja, aproximadamente $85-90 \%$ ao final do primeiro ano. ${ }^{12}$ Nesta mesma época, surgiram alguns trabalhos demonstrando que o TP pode alterar o curso natural das complicações crônicas do DM. ${ }^{5,6,7,8,9,10}$ Foi desenvolvido um trabalho conjunto entre a Universidade de Pádua e a Universidade de Minnesota, onde um grupo de pacientes diabéticos tipo I submetidos ao transplante isolado de pâncreas foi acompanhado por 10 anos. ${ }^{5,6}$ Neste estudo, os autores realizaram biópsia renal protocolar ao final do quinto e do décimo ano para avaliar a evolução das lesões renais. Os resultados demonstraram que as lesões glomerulares induzidas pelo DM desaparecem após 10 anos de transplante de pâncreas bem sucedido. Em outro estudo semelhante, outro grupo acompanhou por 10 anos os pacientes submetidos ao TP de todas as modalidades e avaliaram de forma protocolar a evolução da polineuropatia diabética. ${ }^{7,8}$ Estes autores demonstram que existe uma melhora significativa na condução nervosa periférica demonstrada por eletromiografia, apesar de não haver reversão total das lesões. Finalmente, alguns autores estudaram a evolução da retinopatia diabética pós-TP. ${ }^{9}$ Estes trabalhos demonstraram que, aparentemente, as lesões já estabelecidas na retina não melhoravam. No entanto, a doença retiniana parece estabilizar depois de atingido o estado de euglicemia permanente.

\section{CONCLUSÃO}

O transplante de pâncreas isolado é uma alternativa terapêutica que deve ser oferecida aos pacientes com DM tipo $1 \mathrm{com}$ controle metabólico difícil, hipoglicemia assintomática e complicações crônicas incipientes. O presente artigo relata dois casos transplantados com sucesso no Hospital São Lucas da PUC, em Porto Alegre.

\begin{abstract}
This paper aims to report the first two cases of isolated pancreas transplantation in Rio Grande do Sul, Southern Brazil, as well as to discuss its indications and results. Case 1 - Female, 32 years-old, diabetic since 17 years-old, inadequate metabolic control and presenting with chronic diabetic complications. Transplantation was performed on 12 February 2003 at São Lucas Hospital, PUCRS. Case 2 - Female, 29 years-old, diabetic since 14 years-old, unsatisfactory metabolic control and chronic diabetic complications. Transplantation performed on 02 March 2003. Systemic-bladder drainage was used. Quadruple immunosuppression (induction therapy, tacrolimus, MMF and prednisone) was employed. Clinical outcome was good for both patients, with excellent metabolic control achieved at the end of the first year. We conclude that, in selective patients, pancreas transplant alone is an effective option to control complicated type I diabetes.
\end{abstract}

Key words: Pancreas transplantation - Pancreas transplant alone 